\title{
The Effect of Repeatedly Cooking Oils on Health and Wealth of a Country: A Short Communication
}

\author{
Ram Kumar Deshmukh*
}

Department of Food Science and Technology, Sambalpur University, Odisha, India

\begin{abstract}
Deep frying is the universal, prevalent and one of the most important processes involve in the food processing industry even in the home kitchen. Psychologically thinking of the reason behind is only the economic reason as the oils are expensive and after the first use, there is a lot of oil remaining on the pot, that makes people use it again and again without any concern of the health effect of this oil. Although for a country like India where $60 \%$ of the edible oil imported from the other source of the country which bears a lot of economic expenses. Every year elevation in the price of edible oil which causes people to use the same oil in repeated frying for food. In this review, the paper focuses on the jeopardize effect on health and the statistical and economic analysis on the edible oil in India.

Keywords: Deep frying; Edible oil; Health effect; Economic
\end{abstract}

\section{INTRODUCTION}

It is very often in India people using the same oil again and again to prepare the food to save cost, and frequently carrying out in roadside food stall, hotels and restaurant to save the expenditure and make the profit without knowing the adverse effect of reusing of repeatedly cooking oil. Normally the snacks and the breakfast and fried item of food preparing in repeated cooking oil i.e. samosa, bhajiya, vada pav, papad, banana chips, bhelpuri, puri, dosa, dabeli, jalebi, kachori, pakoda, poha, french fry, pork chops chicken and fish, fried vegetables and many more. People usually don't get it through the taste of the product but inside the metabolism, the composition of the repeated fried oil make sever effect on the interior system of the human body which leads to illness. People always concern when it comes to talking about oil or fat because nobody wants to get obesity or look bad physically. But when the commercialization comes in the way they want only profit. The use of repeated heating oil mostly has seen in a roadside food outlet, hotels, restaurant, and in kitchen. First, understand the mechanism of frying of food what is the modification or changes makes in food when it fried in fresh oil? Secondly the effect of repeatedly frying oil on the food? Deep oil frying/cooking is the process of culinary profession where the food commodity immersed in oil fully or partially at $160^{\circ} \mathrm{C}-190^{\circ} \mathrm{C}$ in the presence of air and moisture [1]. In this process the modification in food commodity brought by the many chemical reactions i.e. thermal oxidation, polymerization, hydrolysis.

\section{Edible oil consumption pattern}

In respect to per $\mathrm{kg}$ capita consumption of edible oil India, somewhat lower with compare to global consumption. In 2012-13 of edible oil in India was about $15.4 \mathrm{~kg}$ which is much lower than the global consumption was $26.3 \mathrm{~kg}$, which is gradually increasing year by year till 2016, 16.2, 17.0, 19.0 in India and 27.0, 30.0, 30.5, globally respectively. But after that, the consumption of edible oil decreased up to some extent 2016-17 18.9 and $28.0 \mathrm{~kg}$ (Table 1). This is due to the increasing awareness regarding the use of oil and fat in the diet and its adverse effect on health. India and globally respectively (Figure 1).

Table 1: Per capita consumption $\mathrm{Kg}$ per annum.

\begin{tabular}{llllll}
\hline Year & $2012-13$ & $2013-14$ & $2014-15$ & $2015-2016$ & $2016-2017$ \\
\hline India & 15.4 & 16.2 & 17 & 19 & 18.9 \\
\hline
\end{tabular}

Correspondence to: Dr. Ram Kumar Deshmukh, Department of Food Science and Technology, Sambalpur University, Odisha, India, E-mail: rkdeshmukh9421@gmail.com

Received: May 20, 2019; Accepted: July 01, 2019; Published: July 25, 2019

Citation: Deshmukh RK (2019) The Effect of Repeatedly Cooking Oils Effects on Health and Wealth of A Country: A Short Communication. J Food Process Technol 10:807. doi: 10.35248/2157-7110.19.10.807

Copyright: (C) 2019 Deshmukh RK. This is an open-access article distributed under the terms of the Creative Commons Attribution License, which permits unrestricted use, distribution, and reproduction in any medium, provided the original author and source are credited. 


\begin{tabular}{llllll}
\hline World & 26.3 & 27 & 30 & 30.5 & 28 \\
\hline
\end{tabular}

and import increased by $6.41 \mathrm{ml} \mathrm{T}(78 \%)$ to match the rising consumption (Figure 2 ).

Between 2008/09 and 2015/16 domestic production decreased by $0.52 \mathrm{ml} \mathrm{T}(-8 \%)$, consumption increased by $6.75 \mathrm{ml} \mathrm{T}(48 \%)$

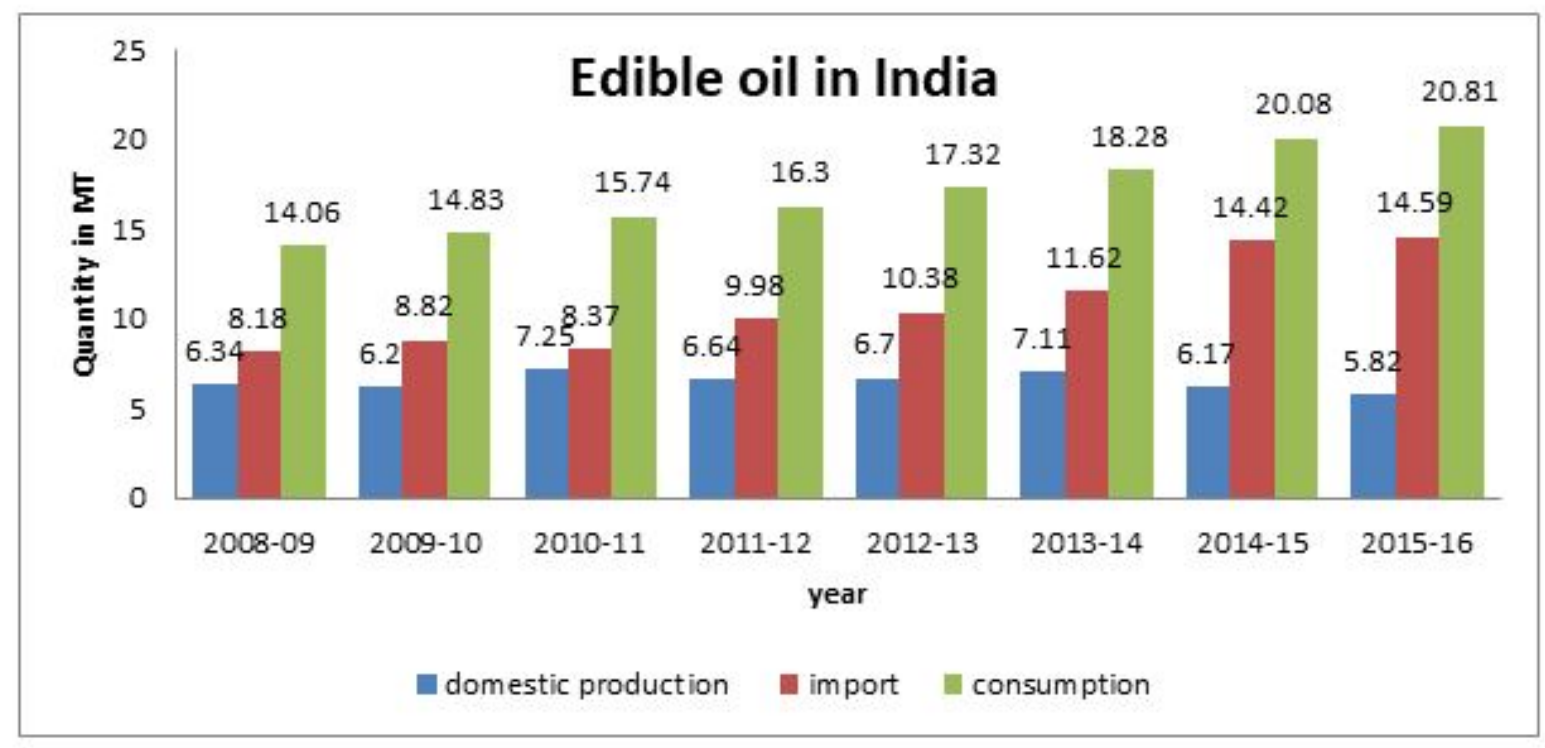

Figure 1: Edible oil production, consumption, and import.

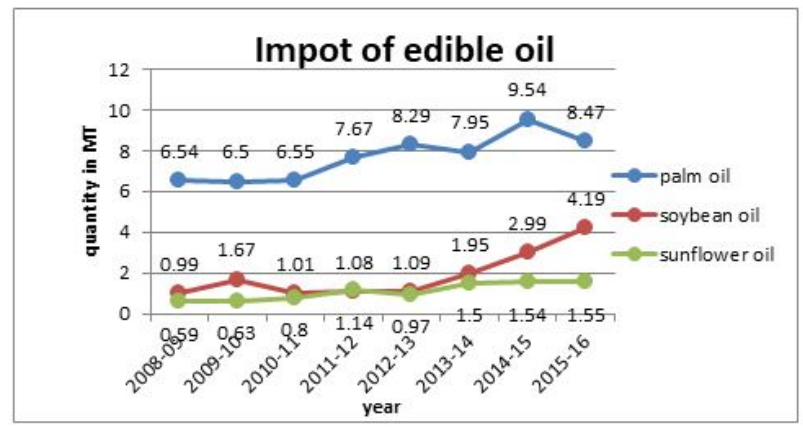

Figure 2: Import of edible oil.

Due to competitive prices, less voyage period, acceptability by the Consumers and blending with other oils, Palm Oil import increased from $6.54 \mathrm{ml} \mathrm{T}$ in $2008-09$ to $8.47 \mathrm{ml} \mathrm{T}$ in 2015-16 while import of Sun Oil increased from only $0.59 \mathrm{ml} \mathrm{T}$ to 1.55 $\mathrm{ml} \mathrm{T}$ and import of Soybean Oil increased from $0.99 \mathrm{ml} \mathrm{T}$ to $4.19 \mathrm{ml} \mathrm{T}$ during the same period.

\section{Production of edible oil}

Domestic production of edible oil was in India in 2008-09 was 6343 thousand which decreased by year and year and in 2009-10 was 6197 which lower by 146 from the previous year but in 2010-11 seemed to accelerate the production in edible oil up to 7253 which increased by 1056but again in 2011-12 again depression in the production by 609 and production was 6644 this year, 6695 increased by 51 for 2012-13, and with the elevation of 412 the production was 7107 in the year 2013-14, in 2014-15 the depression in the production of 936 and in series the depression of 352 with the production of 5819 in the
2015-16 year (Figures in 000 MT). The total depression of the production of edible oil was 524 thousand MT, in the production line, it was depressing in the production of edible oil year by year due to the scarcity of the raw resources. There was a zigzag graph of the production curve which shows the production elevation and depression year by year till 2015-16 (Figure 3).

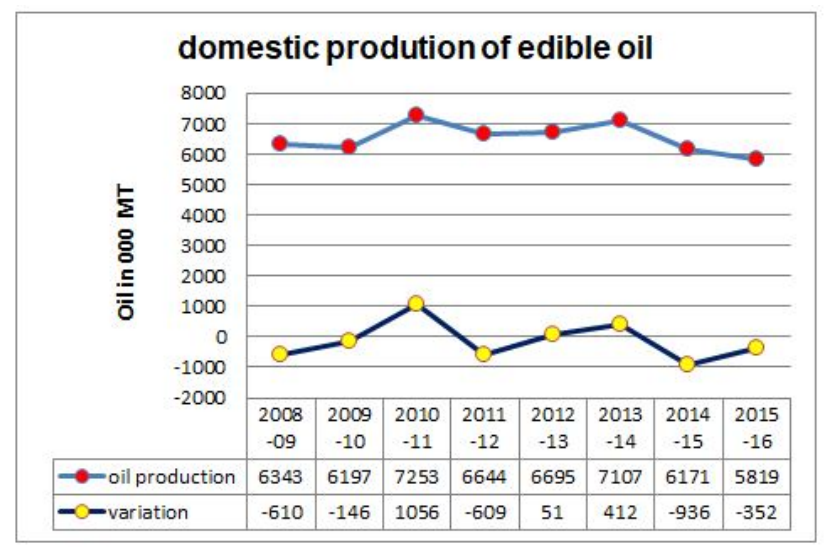

Figure 3: Domestic production in India during the production year 2008 to 2016.

\section{Import of edible oil}

As per ICRA, India involves an unmistakable position on the planet oilseeds industry with a commitment of around $10 \%$ in an overall generation. However, the interest for eatable oils (extricated from oilseeds notwithstanding palm oil) is altogether higher than the household creation, prompting reliance on imports (60\% of a prerequisite) (ICRA report). The demand for the edible oil imported in India during the year 2008 to 2016 
was increasing as the inclined curve which shows the consumption of the imported oil demand increases in the country (Figure 3). The elevation in the demand of the edible oil might be due to the reason of the domestic oil uses mostly like the other purpose than the eating and maybe the possible reason was the quality of the edible oil was better than the domestic produced edible oil. As the population increases the demand of the edible oil also increases because the domestic production of the oil was not enough to fill the requirement of the population the data available shows the consumption of the domestic edible oil production significantly decreases from $45.1 \%$ to $28 \%$ year by year in during 2008 to 2016 . The depression in the consumption of domestic oil might be due to the quality and the other purpose consumption. Import of edible oil around $60 \%$ of domestic demand for edible oils is met through imports.

The total import of edible oils in 2016-17 financial years was 140 Lakh MT. The major edible oils imported are Crude Palm Oil, Soybean Oil and Sunflower Oil which constituted 38.58\%, $24.83 \%$, and $12.31 \%$ respectively of the total imports during F/Y 2016-17, while RBD Palm oil constituted 20.96\% of total edible oil imports (Figure 4). The latter valued at around Rupees 65,000 crores, constituted around $2.5 \%$ of India's total import bill (ICRA report). The government is currently running National Mission on Oilseeds and Oil Palm (NMOOP) to encourage the adoption of newly released varieties and improved agro-techniques in oilseed crops. The mission targets increasing production of oilseeds to 42 MT by FY2022 from estimated 34 MT in FY2017. import obligation on Crude and Refined Palm oils expanded to $30 \%$ and $40 \%$ individually, import obligation on Crude and Refined Soybean oil expanded from to 30\% and $35 \%$ separately, import obligation on Crude and Refined Sunflower oil expanded from to $25 \%$ and $35 \%$ individually and import obligation on Crude and Refined Rapeseed oils expanded to $25 \%$ and 35\% respectively (Department of Food and Public Distribution, Government of India) ICRA estimates that this can help lower the proportion of imports in total edible oil consumption in the country to around 55\% in FY2022 from around $60 \%$ in FY2017, translating into saving of a Rupees 65000 crore of foreign return.

Due to this reason, imported oil consumption increases year by year from $58.2 \%$ to $70.1 \%$. The quantity of oil import elevated year by year and the as the consumption increases (Figure 5). As the people's lifestyle was changing time by time and tend to the junk, fried and fast food the per capita consumption also increased from $11.58 \mathrm{~kg}$ to $15.70 \mathrm{~kg}$ till 2016 . According to the data, the elevation of the per capita consumption is about average about 5.45 (Table 2).

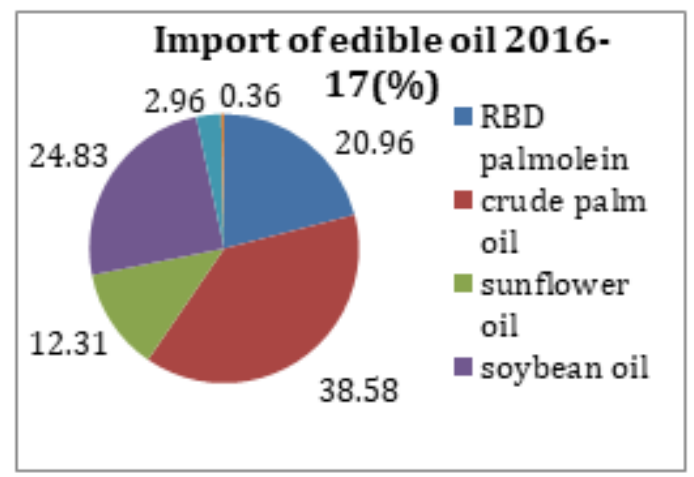

Figure 4: Imports of edible oil\% in 2016-17.

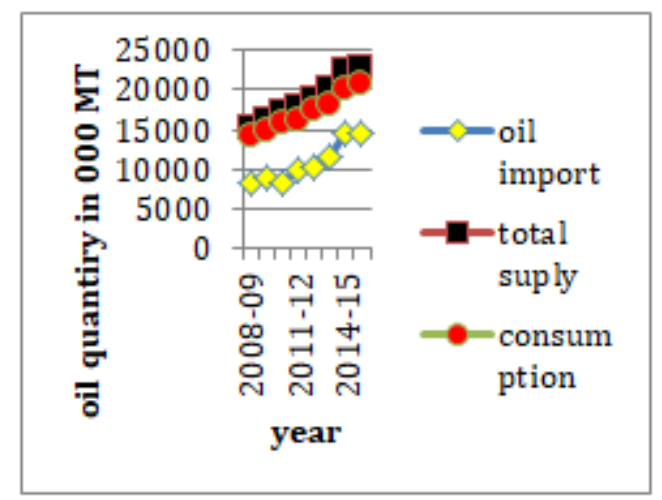

Figure 5: Import of oil, the supply of oil and the consumption of oil graph.

In India, the consumption of edible oil increased rapidly due to socio-economic condition and the lifestyle people today living. Edible oil category the palm oil is the major oil being using after the Soybean Oil (SBO) and mustard oil.

\begin{tabular}{|c|c|c|c|c|c|c|c|c|}
\hline Year & $2008-09$ & $2009-10$ & 2010-11 & $2011-12$ & $2012-13$ & 2013-14 & $2014-15$ & $2015-16$ \\
\hline domestic oil consumption $\%$ & $45.10 \%$ & $41.80 \%$ & $46.10 \%$ & $40.80 \%$ & $38.70 \%$ & $38.90 \%$ & $30.70 \%$ & $28 \%$ \\
\hline imported oil consumption\% & $58.20 \%$ & $59.50 \%$ & $53.20 \%$ & $61.20 \%$ & $60.00 \%$ & $63.60 \%$ & $71.80 \%$ & $70.10 \%$ \\
\hline per capita consumption $\mathrm{kg}$ & 11.58 & 12.05 & 12.62 & 12.89 & 13.53 & 14.41 & 15.31 & 15.7 \\
\hline growth in per capita cons & $12.33 \%$ & $4.06 \%$ & $4.74 \%$ & $2.17 \%$ & $4.93 \%$ & $4.32 \%$ & $8.51 \%$ & $2.51 \%$ \\
\hline
\end{tabular}

Table 2: Consumption of oil and per capita consumption.

\section{Health effect of the repeated heating oil}

There were an estimated 18 million cancer cases around the world in 2018, of these 9.5 million cases were in men and 8.5 million in women. After lung (12.3\%) and breast cancer 
(12.3\%), Colorectal cancer is the third most common cancer $(10.6 \%)$ new cases in 2018. With this growing global burden, prevention of cancer is one of the most significant public health challenges of the 21st century. Our Cancer Prevention Recommendations work together as an overall way of living healthily to prevent cancer through changing dietary patterns, reducing alcohol consumption, increasing physical activity and achieving and maintaining a healthy body. Louise Meincke, World Cancer Research Fund International's Head of Policy and Public Affairs stated that the increasing availability, affordability, and acceptability of 'fast foods' are contributing to rising rates of obesity worldwide. That's why change needs to happen at both a policy and an individual level. Overweight and obesity, generally assessed by various anthropometric measures including Body Mass Index (BMI) and waist circumference, are now more prevalent than ever.

In 2016, an estimated 1.97 billion was adults. In this study, they used two model normal male rats and ovariectomized female rat for the study of prolonged consumption about 4 months of repeatedly heating palm and soy oil and also oxidative stability of both compared. When the peroxide value of palm and soy oil measured after 5 times heating the value found significantly elevated compared to one time heated and fresh oil respectively [2]. Fresh and five times heated soy oil has greater peroxide value than same treated palm oil that proofs the palm oil has greater heat stability than soy oil due to their fatty acid structure. According to American Oil Chemist Association (AOCS), five times heated oil having greater peroxide value of edible oil $(>140$ $\mathrm{Meq} / \mathrm{kg}$ ) than the less number of heating treatment. For plasma lipid peroxidation on the animal (male and ovariectomized female rats) treatment that value measured in terms of TBARS value which is significantly higher in the male rat which was orally treated with containing $15 \%$ once and five-time heated palm oil and soy oil for four months compared to control. They found that five times heated oil-fed rats TBARS value than once heated oil group respectively. But with the comparison with soy and palm oil separately in which clearly shown that palm oil treatment has significantly lower TBARS value than soy oil.

\section{DISCUSSION}

Cooking oil is the first and most fundamental fixing which is utilized in cooking. Each Indian family unit utilizes cooking oil regularly to set up their suppers. In the event that this fixing is utilized consistently and in each family unit, it is essential for us to choose the correct cooking oil for our general wellbeing. At first, the pattern was to choose one specific cooking oil that was reasonable for cooking and afterward, stick to it for eternity. This pattern was pursued presumably in light of the fact that there were very few choices accessible around then. Be that as it may, today, their wide scope of cooking oils accessible in the market. These incorporate are rice grain cooking oil, coconut oil, mustard oil, olive oil, nut oil, sunflower oil, and even ghee. Changing or pivoting oils frequently is solid as it gives the body the diverse fundamental unsaturated fats which it requires. By doing this you can guarantee a great mix of unsaturated fats, nutrients, omega-3, and omega- 6 fats. In addition, supplanting awful fats like immersed and trans fats with more advantageous choices like monounsaturated and polyunsaturated fats is helpful for keeping up a sound heart. Cooking oils with high measures of mono-and polyunsaturated fats will deteriorate more than those with just soaked unsaturated fat. Then again, cooking oil with a low "smoke point" will separate quicker, each time it is warmed for cooking or fricasseeing. Having particulate issue fall into the fricasseeing oil will quicken the decay. Overwarming of the oil will likewise separate it quicker. Separated oil will result in synthetic concoctions that may be unsafe for the body. Additionally, the separated synthetics likewise bestow a terrible taste to the nourishment, making it less alluring for utilization. That is the reason fricasseeing oil should be changed or supplanted as often as possible. You can do this by picking more advantageous non-tropical vegetable oils for preparing and getting ready nourishment. As a rule, you ought to pick oils with under four grams of soaked fat per tablespoon, and no incompletely hydrogenated oils or trans fats. You may likewise locate that a few oils have an interesting taste, so attempt diverse sorts to find which ones you like. Additionally, a few oils are better for particular kinds of cooking than others, so you could even keep more than one sort of cooking oil in your storeroom. For example, utilize olive oil for planning servings of mixed greens, mustard oil for vegetables, ghee for paranthas and rice grain oil for heating. This will guarantee that your body gets all the essential supplements which are vital for the body.

Using repeated frying oil is a regular procedure in the kitchen of household, roadside stall, hotels, and restaurants in order to lower the production cost or raise the profit margin at a professional level. But people ignore the impact of using repeated frying/heating oil on health for making for short time profit/saving money. The consumption of the food prepared from repeated frying/cooking oil can make ill to a human being for the long run. The repeating the heating or frying induce the physical and chemical changes which are not good for human consumption. As per the country economic survey, the production of the edible oil and the import ration is very low in India that is subject of concerning over the best use of the cooking oil for the betterment of health and wealth of country. The utilization of repeated cooking oil is still a matter of concern over the health point of view and waste management in India and worldwide also.

\section{REFERENCES}

1. Nayak PK, Dash U, Rayaguru K, Krishnan KR. Physio-chemical changes during repeated frying of cooked oil: A review. J Food Biochem. 2016;40:371-390.

2. Ganesan K, Sukalingam K, Xu B. Impact of consumption of repeatedly heated cooking oils on the incidence of various cancersA critical review. Critical reviews in food science and nutrition. 2019;59:488-505. 